to managing addiction, and how similar they are to those employed in services in the United Kingdom. Thailand has its own equivalent of our non-statutory agencies, in the form of the Buddhist temples, which receive some government subsidy and which employ herbal medicine, meditation, and spiritual means to achieve and sustain abstinence.
What did come across, time and again, was how poorly prepared many developing countries are to implement prevention and treatment and rehabilitation programmes. If more effort, funding and international cooperation can be put into demand reduction in the future, then this Summit will not have been wasted.

\title{
The National Conference on Alcohol: Towards a national policy?*
}

\author{
David G. WALbRIDGe, Senior Registrar in Psychiatry, Littlemore Hospital, Littlemore, \\ Oxford OX4 4XN
}

The annual cost of alcohol misuse in Britain has been estimated at $£ 2,000$ million. This figure includes the cost of alcohol-related ill health, the consequences of crime and road traffic accidents, and the impact of excessive drinking on industry.

In his keynote address, Sir Geoffrey Howe, in his capacity as Chairman of the Ministerial Group on Alcohol Misuse, outlined the government's present range of policies for reducing the level of alcohol misuse and some of the possibilities for the future. What cannot now be denied, however much the drinks industry would like to, is that the price of alcohol in relation to mean disposable income determines the level of alcohol consumption within a given society. Consumption in turn, correlates very closely with the prevalence of alcohol-related problems. Broadly speaking, policies may be aimed either at reducing overall alcohol consumption or at addressing the factors involved specifically in the misuse of alcohol - "anti-alcohol" versus "anti-misuse" in the words of Dr John Rae, Director of the Portman Group.

The main anti-alcohol measure is for the government to increase the excise duties levied on the sale of alcohol, but this is not without adverse consequences. Moderate drinkers are forced to pay more for their pleasure, the retail price index is pushed up, falling sales jeopardise employment and exports in the drinks industry and, taken too far, increased duties may result in reduced revenue for the exchequer. Professor Griffith Edwards proposed that a compromise might be to maintain the supply of alcohol at its present level by economic action in order that the benefits of anti-misuse initiatives should not be washed away in a "tide of liquor". Fortunately, EC policy is for alcohol taxation to remain under the control of individual governments

*Held on 6 April 1990 at The John Radćliffe Hospital, Oxford. and, if anything, alcohol consumption in Britain has fallen slightly over the past decade.

There is a wide range of possible anti-misuse policies which could be applied or co-ordinated at a national level. Medical lobbying in France by Professor of Public Health, Gerard Dubois and his colleagues has recently resulted in legislation which almost completely bans alcohol advertisements. By contrast, advertising in Britain is controlled by a voluntary code of practice which outlaws the specific targeting of young age groups but continues to allow the portrayal of drinking as associated with social success. The pricing of low-alcohol drinks might also be an area amenable to legislation, and the introduction of random breath testing by roadblock is resisted only by the government; all other parties, including the NCCL, are in favour.

Research suggests that a young onset of drinking is associated with later alcohol misuse and, although causality is not clearly established, it would seem reasonable to seek to reduce under-age drinking. Publicans are already receptive to the idea of identity cards for young drinkers, as a recent change in the law makes it an offence to serve under-age drinkers whether knowingly or not. From the point of view of the civil liberties movements, identity cards meet with certain reservations, but it would be hard to object to well-monitored, voluntary schemes run at a local level.

In the workplace, alcohol is a surprisingly costly factor when accidents, sick leave, erratic workmanship and slipshod management decisions are taken into account. As well as banning alcohol from the workplace (as London Transport has done), much can be done to promote awareness that problems may exist in up to $10 \%$ of the work force. The incentive for individual companies to address this issue might well come from considering the experience of Mr Bob Randall, who described how his programme at GEC for the identification and 
rehabilitation of problem drinkers had brought about very considerable financial savings.

In conclusion, the way forward is likely to consist of a multi-faceted set of policies, co-ordinated at a national level and embracing such elements as economic control of the alcohol supply, legislation and specific policies directed at the prevention, detection and treatment of alcohol misuse in a variety of settings.

\title{
'Achieving Resource Management': a national exhibition and conference
}

\author{
R. N. BLooR, Consultant Psychiatrist, Substance Abuse Unit, City General Hospital, \\ Stoke-on-Trent ST4 6QG
}

This meeting, held at the New Connaught Rooms, London, on 6 April 1990, attracted over 400 delegates of a wide variety of backgrounds, including managers, clinicians and computer experts. It started with a plenary session with two main speakers from the Department of Health followed by Professor Chantler from Guy's. If, heaven forbid, I was involved with the management of the Department of Health, I would avoid at all costs allowing the Deputy Chief Medical Officer, Dr Diana Walford, to illustrate her opening address at a conference on the use of information technology and resource management with totally unreadable slides, accompanied by the explanation that the Department of Health were "trying out a new graphics package which didn't work".

The next speaker, Sheila Masters, Director of Finance of the NHS Management Board, steered clear of the graphics package but proceeded to introduce her talk on a national perspective of resource management by announcing that "there is not enough time allowed for me so I will have to get through this at a gallop!". There may have been those present, who like me, felt these two speakers inadvertently summed up the Government's approach to resource management and information technology within the NHS into three very concise nutshells, poor planning, inadequate testing and an unrealistic timescale.

The content of the first two presentations was predictable: Dr Walford assured us that what clinicians needed was patient-based credible information and resource management would provide this once it was introduced, while Sheila Masters defined the aim of resource management as providing more and better patient care through better use of resources.

It was left to Professor Chantler to look at some of the more practical aspects of the introduction of resource management and his message, that you have to get the management structures right first and then get the information systems into the management structure, was one of the key statements of the day.
For those of us not in resource management systems, this rather negated the rest of the day, which consisted of a series of one-hour presentations from eight of the major computer companies involved in information technology supply in the resource management area.

Presentations ranged from the very smooth to the extremely rough and varied considerably in their contact with reality. It was difficult at the end of the day to understand what the purpose of the conference had been. I learnt nothing new about resource management, the one-hour presentations were blatantly subjective and sales-orientated and provided little more than a sponsored elephant trap for the salesman.

The redeeming feature of the day was, however, the exhibition where, tucked away in a quiet corner away from the hype and sales pitch, were a team from Yorkshire Health Authority. They had a welldesigned exhibition of what resource management is about and they provided copies of the Government information package for resource management initiatives in acute hospitals as well as a short $\mathrm{DoH}$ handbook on getting started on resource management. Their presentation was lucid, informative and objective and clearly outlined the major steps of consultation, education and negotiation which need to be undertaken before even thinking about talking to computer salesmen.

Resource management is clearly a fact and, as Sheila Masters pointed out, resource management is not information technology. Unfortunately this conference attempted to address both issues and failed to do either. The Yorkshire Regional Health Authority have a range of publications available-you can contact them at Jesmond House, Victoria Avenue, Harrogate, 0423-500066, for a publication order form and a review of resource management based on experience, commonsense and reality. Something which appeared sadly lacking from the other presenters at this national meeting. 